04

\title{
Поляризационная память в фотоанизотропных средах для голографии на базе битуминозных материалов
}

\author{
(C) В.И. Тарасашвили, С.С. Петрова, А.Л. Пурцеладзе, В.Г. Шавердова, Н.З. Оболашвили \\ Лаборатория голографической записи и обработки информации, Институт Кибернетики, \\ Грузинский технический университет, \\ 0186 Тбилиси, Грузия \\ e-mail: v_tarasashvili@mail.ru
}

Поступила в редакцию 22.01.2018 г.

В окончательной редакции 04.06.2018 г.

Исследованы фотоанизотропные свойства поляризационно-чувствительных люминесцентных сред для голографии на базе битуминозных материалов. Обнаружен эффект памяти фотолюминесценции к линейной поляризации возбуждения в грузинских сырых нефтях и в автомобильных бензинах с различным октановым числом. Получены спектры фотолюминесценции, поляризационные спектры и измерены поляризационные характеристики сред в зависимости от их химической структуры и состава. Получена отражательная голограмма Денисюка в люминесцентном фотоанизотропно-гиротропном материале с использованием линейно поляризованного когерентного света и исследована ее поляризационная характеристика.

DOI: $10.21883 /$ OS.2018.10.46707.18-18

\section{Введение}

Ф. Вейгертом было открыто два поляризационных эффекта в фоточувствительных средах: 1) возникновение частично поляризованной люминесценции, испускаемой раствором красителя при возбуждении его поляризованным излучением (поляризационная память фотолюминесценции) и 2) фотоиндуцированная анизотропия поглощения света в химических системах галогенидов серебра под действием актиничного поляризованного света $[1,2]$. Поляризационные эффекты поглощения света легли в основу работ Ш.Д. Какичашвили, создавшего в 70-е годы новый поляризационно-голографический метод записи и реконструкции волнового фронта анизотропно-гиротропного объекта [3]. Основная сущность метода заключается в том, что в качестве голограммных сред используются светочувствительные материалы, приобретающие под действием поляризованного излучения анизотропию и гиротропию, которая моделирует состояние поляризации суммарной волны; зарегистрированная в подобной среде голограмма оказывается способной однозначно реконструировать векторное поле объекта. Таким образом, вопрос о регистрирующей среде в поляризационной голографии является центральным, что определяет особый интерес и требования к регистрирующим материалам [4-6].

В работе [7] нами впервые было предложено использовать в качестве голограммных сред светочувствительные материалы, в которых под действием поляризованного света возникает частично-поляризованная люминесценция (эффект Вейгерта). К преимуществам поляризационно-чувствительных сред для голографии, базирующихся на феномене люминесценции, можно отнести:

- сверхвысокую светочувствительность;
- высокую скорость отклика - процесс люминесценции происходит в наносекундной шкале времени, его очень выгодно использовать для динамической поляризационной голографии;

- совместимость с живыми организмами - исследования с использованием видимого люминесцентного света не влияют на процессы, происходящие в клетке;

- высокое пространственное разрешение, имеющее решающее значение в исследованиях разных систем на микроскопическом уровне.

Особый интерес представляет возможность мультиплексной записи и наблюдения за несколькими анизотропно-гиротропными объектами одновременно, если они закодированы разными частотами эмиссии и состоянием поляризации. Это открывает возможность варьирования спектральным составом излучения как на стадии записи, так и на стадии считывания информации.

В настоящее время нами проводятся работы по получению и исследованию фотоанизотропных люминесцентных сред для голографии на базе различных материалов с выраженными эффектами векторных реакций. Весьма перспективным материалом для записи поляризационнолюминесцентных голограмм оказались среды на базе битуминозных материалов, проявляющих заметную поляризованную фотолюминесценцию в широком спектральном диапазоне. Физические и химические свойства сред на базе битуминозных материалов, в том числе грузинской нефти и нефтепродуктов (NP), подробно исследованы в ряде работ, имеющих как научное, так и практическое значение [8-10].

Целью данной работы является детальное исследование поляризационных характеристик битуминозных фотоанизотропных голограммных сред полученных на базе грузинской сырой нефти и нефтепродуктов (NP) а также проведение экспериментов по записи отражательной 
голограммы Денисюка в битуминозных фотоанизотропных голограммных средах с использованием линейно поляризованного когерентного света и исследование их поляризационных свойств.

\section{Материалы и методика измерений}

Объектом нашего исследования являлась грузинская сырая нефть Сацхенисского месторождения из различных буровых, а также автомобильные бензины марок: AI-92, AI-95 и AI-98 с октановым числом соответственно 92, 95, 98.

В качестве метода исследования фотоанизотропных люминесцентных сред на базе различных битуминозных веществ использован метод поляризационных спектров. С его помощью удается определять взаимное расположение поглощающих и излучающих осцилляторов в молекулах, а также устанавливать связь между симметрией молекул и степенью поляризации индуцированной фотолюминесценции.

Исследования поглощения и поляризованной люминесценции проб образцов проводились в кварцевых кюветах толщиной $4 \mathrm{~mm}$. Спектры поглощения получены на спектрофотометре „Specord UV-VIZ“, модифицированном для поляризационных измерений. Количественные измерения фотоанизотропных характеристик индуцированной поляризованной фотолюминесценции проводились на спектрофлуориметре, собранном нами на основе монохроматора UM-2 и снабженном поляризационными призмами Глана, что давало возможность измерять поляризационные и люминесцентные характеристики исследуемых сред.

Схема спектрофлуориметра приводится на рис. 1. Образцы засвечивались излучением лазера - LSR 405 NL-50, длина волны возбуждающего излучения $405 \mathrm{~nm}$. На пути возбуждающего луча устанавливался линейный поляризатор $P_{1}$ (призма Глана). Световой луч лазера фокусируется линзой $O_{1}$ на исследуемый образец $F$. Точка пересечения луча с поверхностью образца проецируется объективом $O_{2}$ на входную щель спектрофлуориметра $M$, откалиброванного по пропусканию и по длинам волн с точностью $\pm 1 \mathrm{~nm}$. Угол установки образца выбирается таким, чтобы возбуждающий свет, зеркально отраженный от образца, не попадал в объектив $\mathrm{O}_{2}$ и, следовательно, в монохроматор. Таким образом, на входную щель монохроматора проецируется спектр люминесценции образца и диффузно рассеянного возбуждающего света. После прохождения линейного поляризатора $P_{2}$ (анализатора), имеющего возможность поворачиваться относительно электрического вектора возбуждающего излучения, люминесценция попадает на чувствительный фотоприемник PEM - РМТ-62, откалиброванный по спектральной чувствительности и скомпенсированный по темновому току. Спектрофлуориметр обеспечивал корректировку спектров флуоресценции на

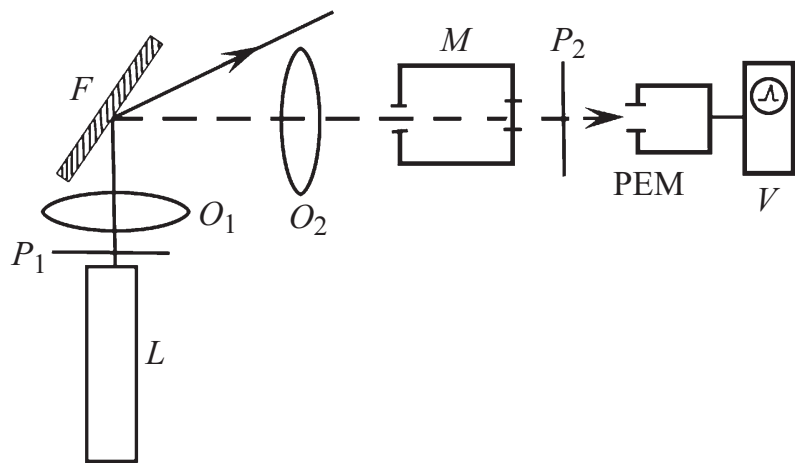

Рис. 1. Оптическая схема спектрофлуориметра для измерения параметров поляризованной люминесценции. $F-$ образец; $L$ - лазер; $O_{1}, O_{2}-$ объективы; $M-$ монохроматор; $P_{1}-$ линейный поляризатор (призма Глана); $P_{2}-$ анализатор; PME - РМТ-62; $V$ - измерительное устройство.

интенсивность возбуждающего излучения и на чувствительность $P M T$. Электрический сигнал с $P M T$ поступает на измерительное устройство $V$. Снимая показания измерительного устройства при различных положениях барабана UM-2 и при ориентациях анализатора $P_{2}\left(0^{\circ}\right.$ и $90^{\circ}$ ) относительно электрического вектора возбуждающего излучения, получаем данные для построения поляризационных спектров люминесценции. Поворот поляризации лазерного излучения приводил к повороту плоскости поляризации $F L$, что вызывало модуляцию интенсивности $F L$ после прохождения через анализатор $P_{2}$; влияние поляризации света возбуждения на параметры $F L$ может трактоваться как поляризационная память люминесценции [11].

Получены спектры индуцированной фотолюминесценции $(F L)$ и поляризационные спектры исследуемых образцов. Степень поляризации люминесценции $P$ измерялась по формуле

$$
P=\frac{I_{0}-I_{90^{\circ}}}{I_{0}+I_{90^{\circ}}}
$$

здесь $I_{0}$ и $I_{90^{\circ}}$ - интенсивности взаимно перпендикулярно поляризованных компонент люминесценции.

На исследуемых образцах сырой нефти и образцах автомобильных бензинов проведена серия экспериментов по поляризационной записи люминесцентных голограмм с использованием линейно поляризованного когерентного света. Голограммы записывались по классической оптической схеме, предложенной Ю.Н. Денисюком [12]. Оптическая схема установки, приведенная на рис. 1, при несложной модификации позволяет осуществить запись и реконструкцию динамических поляризационных люминесцентных отражательных голограмм Денисюка. В качестве анизотропно-гиротропного объекта служило плоское зеркало с внешним алюминированием поляризующий оптический элемент, удовлетворяющий теоретическим условиям, необходимым для адекватной реконструкции векторного поля объекта [13]. Объект 
располагается непосредственно за кварцевой кюветой с пробами образца на базе битуминозных материалов и освещается линейно поляризованным излучением лазера через слой голограммной среды. Отраженные от объекта волны распространяются назад к этому же слою. В результате наложения падающего и отраженного излучения возникает система стоячих волн - интерференционное поле во встречных пучках, передающее все особенности волнового фронта объекта, т. е. динамическая поляризационная люминесцентная голограмма $[14,15]$.

Для поляризационного анализа пучок, соответствующий восстановленному мнимому изображению объекта, проецировался объективом $\mathrm{O}_{2}$ на блок эмиссионных фильтров. После прохождения фильтра, где происходит отбор длин волн из требуемого интервала спектра люминесценции и блокирование возбуждающих длин волн, сигнал падал на поляризационно-голографическую дифракционную решетку анизотропного профиля, затем на фазовую пластинку $\lambda / 4$, на линейный поляризатор $P_{2}$ (анализатор), и на фотокамеру. Эмиссионный фильтр, решетка анизотропного профиля, пластинка $\lambda / 4$ и фотокамера на рис. 1. не показаны.

Как известно, запись дифракционной решетки анизотропного профиля осуществляется двумя когерентными пучками равной интенсивности со взаимно ортогональными произвольными состояниями поляризации на поляризационно-чувствительной среде [16]. При записи в фотоанизотропном материале возникает поле анизотропного профиля, соответствующее суммарному полю с периодически изменяющейся по направлению осью комплексного двулучепреломления. Подобные решетки способны разлагать поступающее на них излучение на ортогональную (линейную и циркулярную) компоненты, размещая их, соответственно, в положительные и отрицательные порядки, что позволяет использовать решетку в оптических системах в качестве анализирующего элемента поляризации. В нашем случае дифракционная решетка анизотропного профиля также получена на высокочувствительном фотоанизотропно-гиротропном материале на базе органического красителя ПЧЖ, введенного в желатиновую матрицу. Запись решетки осуществлялась пучками циркулярной поляризации (правая и левая) на длине волны $488 \mathrm{~nm}$.

\section{Результаты и обсуждение}

На рис. 2 изображены экспериментально полученные поляризационные спектры $(a)$ и спектры люминесценции $(b)$ исследуемых образцов сырой нефти из различных буровых. При одинаковых условиях наведения анизотропии фотолюминесценции $(405 \mathrm{~nm}, 30 \mathrm{~mW})$, пробы из буровой № 2 имеют наибольшие значения абсолютных величин степени поляризации $F L$ (параметр $P$ ), в то время как пробы из буровой № 1 имеют минимальные значения этого параметра. Максимальные значения ин-
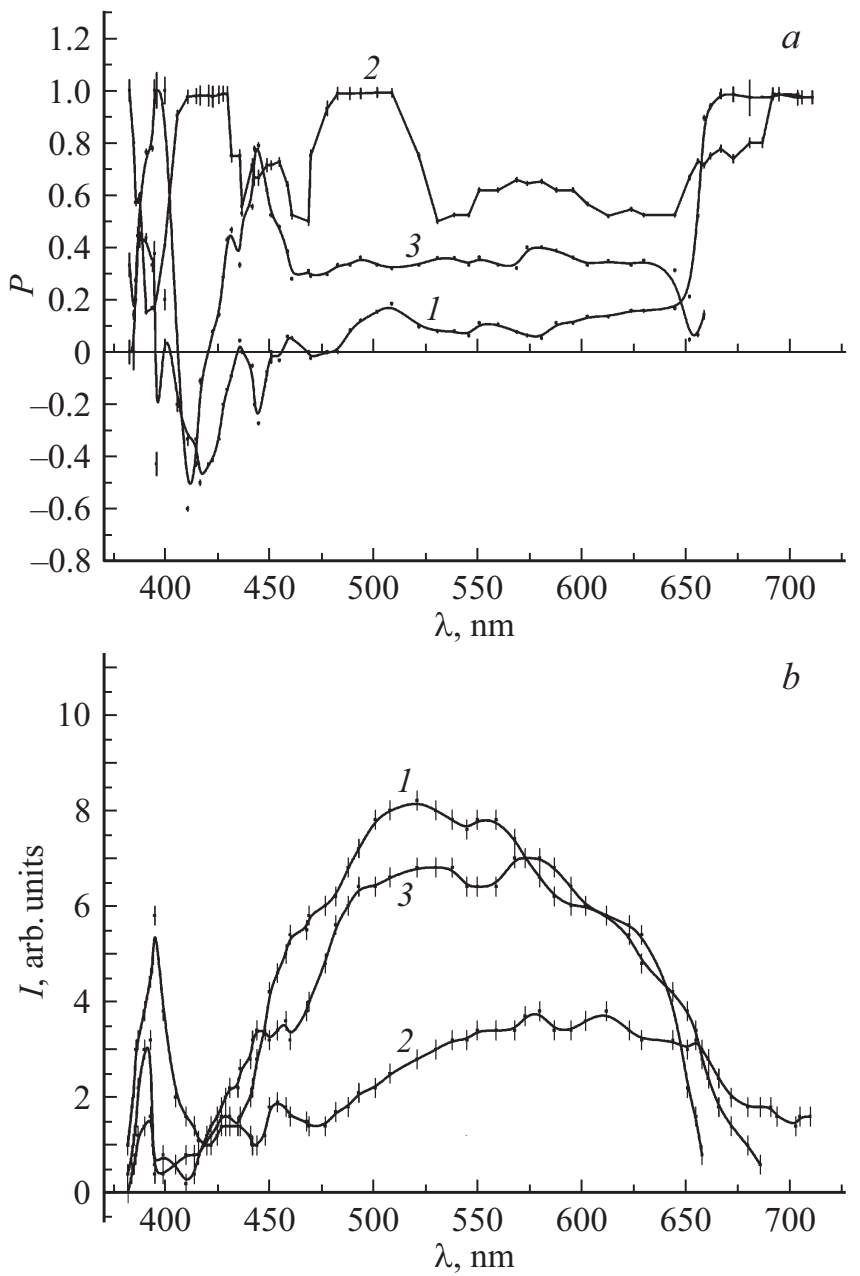

Рис. 2. Поляризационные спектры $(a)$ и спектры люминесценции $(b)$ исследуемых образцов сырой нефти из буровых 1 (кривая 1), 2 (кривая 2), 3 (кривая 3).

тенсивности люминесценции $I$ имеют нефтяные пробы из буровой № 1.

Как известно, сырая нефть - многокомпонентная система, состоящая в основном из различных типов углеводородов. В нее входят предельные парафиновые углеводороды $\left(\mathrm{C}_{n} \mathrm{H}_{2 n+2}\right)$, нафтены - алифатические углеводороды предельного характера $\left(\mathrm{C}_{n} \mathrm{H}_{2 n}\right)$, ароматические углеводороды (бензол и его высшие гомологи), непредельные углеводороды ряда этилена $\left(\mathrm{C}_{n} \mathrm{H}_{2 n}\right)$, сложные высокомолекулярные углеводороды и некоторые другие вещества. Наблюдаемая люминесценция нефти представляет суммарное свечение всех ее многочисленных люминесцирующих компонентов, поэтому спектр люминесценции проб образцов зависит не только от качественного, но и от количественного состава нефти. Из теории известно, что степень поляризации свечения уменьшается с увеличением симметрии молекул. Молекулы нефтеносных битумов более симметричны, чем молекулы битумов, образованных органическими веществами в приповерхностных слоях почвы, поэтому 

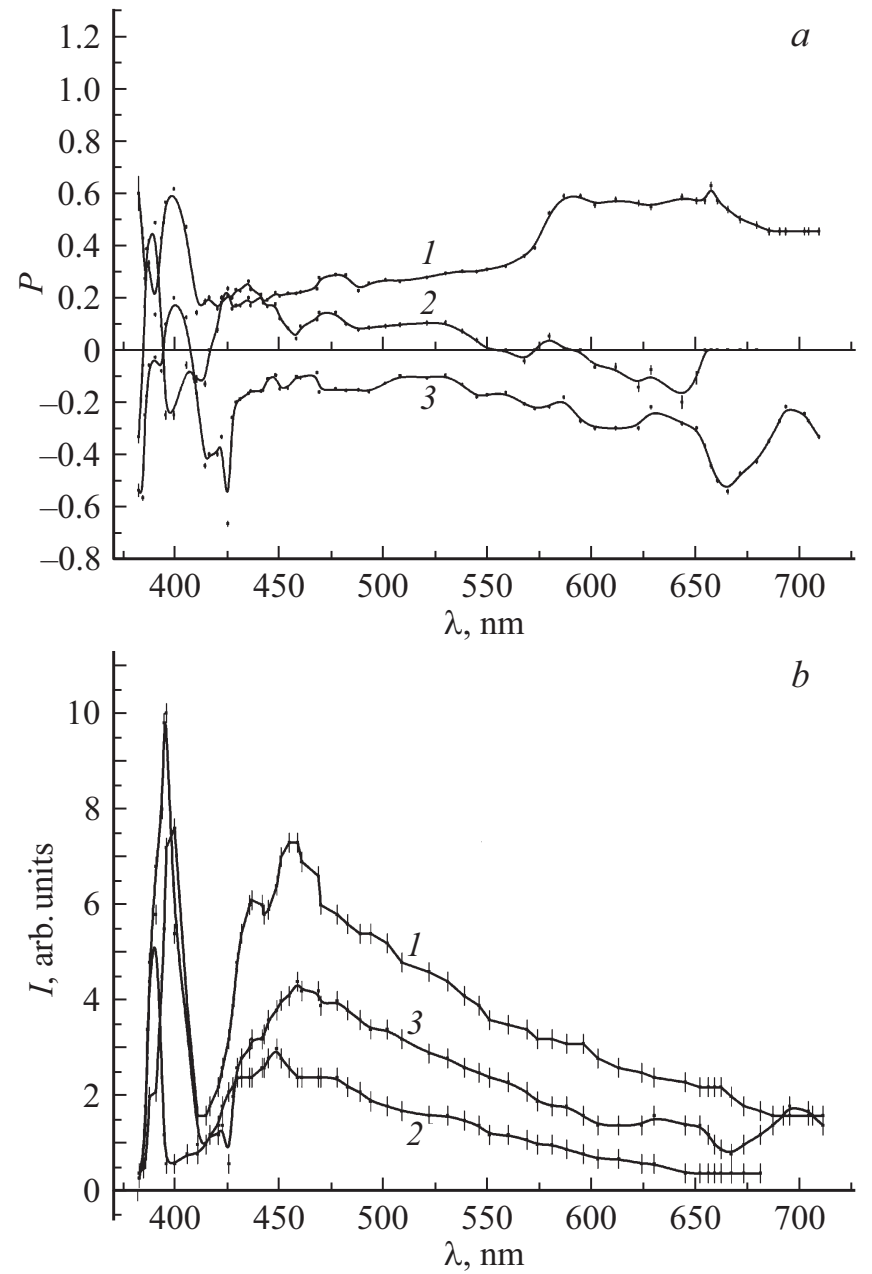

Рис. 3. Поляризационные спектры (a) и спектры люминесценции $(b)$ образцов автомобильных бензинов: кривая 1 - AI-92, кривая 2 - AI-95, кривая $3-\mathrm{AI}-98$.

по величине степени поляризации люминесценции образца можно судить о природе молекул, находящихся в пробе [17]. Полученные значения параметров $P$ и $I$ дают основание предположить, что в нефтяных пробах из буровой № 1 Сацхенисского месторождения, объемное содержание молекул нефтеносных углеводородов больше, чем у проб из остальных буровых $(2,3)$.

На рис. 3. изображены экспериментально полученные поляризационные спектры $(a)$ и спектры люминесценции $(b)$ образцов автомобильных бензинов марок: AI-92, AI-95 и AI-98.

Особый интерес представляет тот факт, что под действием возбуждающего линейно-поляризованного излучения $(405 \mathrm{~nm}, 30 \mathrm{~mW})$, при изменении значения октанового числа бензина, наблюдается не только изменение абсолютной величины степени поляризации фотолюминесценции, но и изменение знака параметра $P$. Для пробы бензина марки: AI-92 с октановым числом 92 параметр $P$ положительный во всем спектральном диапазоне поляризованной люминесценции. Для пробы бен- зина марки AI-95 параметр $P$ знакопеременный: в спектральном диапазоне 420-550 nm $P>0$, а в спектральном диапазоне 560-650 nm $P<0$. Для пробы бензина марки AI-98 $P<0$ во всем спектральном диапазоне индуцированной анизотропии $F L$.

Максимальное значение интенсивности люминесценции наблюдается у пробы бензина марки AI-92, а у пробы бензина марки AI-95 значение интенсивности люминесценции минимально.

Наблюдаемые особенности характера наведенной поляризованным светом анизотропии $F L$ образцов автомобильных бензинов различных марок (с различными октановыми числами) могут быть интерпретированы с помощью модели анизотропного осциллятора [18]. Перемена знака (поворот плоскости преимущественных колебаний на 90) поляризации свидетельствует о том, что анизотропные излучающие осцилляторы, при фиксированной длине волны возбуждающего света, имеют пространственную ориентацию, отличающуюся от ориентации поглощающего осциллятора. Это изменение направления осцилляторов может быть истолковано либо динамически - как поворот осциллятора за время существования возбужденного состояния на некоторый угол $\alpha$, определяемый величиной поглощенного кванта, либо статически - с точки зрения раздельных осцилляторов поглощения и излучения.

Современные автомобильные бензины представляют собой смесь компонентов, получаемых в результате различных технологических процессов переработки нефти. В зависимости от марки, автомобильные бензины готовят на основе бензинов прямой перегонки, каталитического крекинга и каталитического риформинга. Люминесценция автомобильных бензинов может быть связана с содержанием в их составе конденсированных ароматических соединений. Люминесценция высокооктановых бензинов (AI-95, AI-98) может определяться наличием в их составе различных присадок, в ряду которых используются металлоорганические соединения, дающие люминесценцию в видимой области спектра. Состав и соотношение компонентов бензинов зависит от требуемых свойств углеводородных топлив [19].

Как следует из анализа экспериментально полученных нами поляризационных спектров, с изменением марок (AI-92, AI-95 и AI-98) образцов автомобильных бензинов наблюдаются характерные изменения степени поляризации, в частности, изменение абсолютной величины и перемена знака. Отметим также, что поляризационные спектры тесно связаны с химической структурой исследуемых веществ и в некоторых случаях могут быть более характерными, чем спектры поглощения и люминесценции.

На рис. 4. представлена картина дифракции восстановленного изображения волнового поля объекта на решетке анизотропного профиля (при регистрации фотографии анализатор $P_{2}$ параллелен поляризатору $P_{1}$ ). В центре видно недифрагированное частично линейно поляризованное изображение объекта (нулевой порядок 


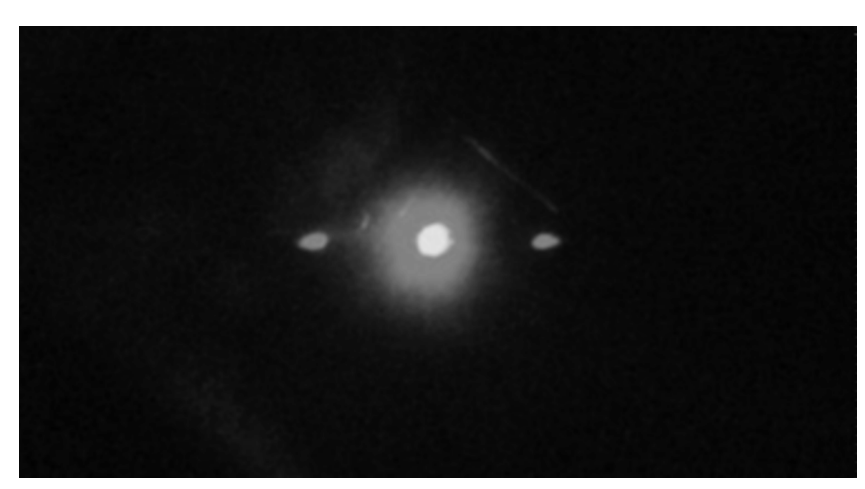

Рис. 4. Картина дифракции восстановленного изображения волнового поля объекта на решетке анизотропного профиля (при регистрации фотографии, анализатор $P_{2}$ параллелен поляризатору $\left.P_{1}\right)$.

дифракции). Слева и справа от него право- и левоциркулярно поляризованные пучки, дифрагированные соответственно в +1-й и -1-й порядки. В случае, когда картина дифракции восстановленного изображения регистрируется положением анализатора $P_{2}$, перпендикулярного поляризатору $P_{1}$, интенсивность нулевого порядка минимальна, но не равна нулю. Это показывает, что состояние поляризации восстановленного поля объекта частично линейно поляризовано.

В качестве голограммной среды служили образцы сырой нефти из буровой № 2, имеющие наибольшие значения абсолютных величин степени поляризации фотолюминесценции (параметр $P$ ) в интервале длин волн $(470-540 \mathrm{~nm})$. После прохождения фильтра, выделяющего требуемый интервал длин волн $(450-520 \mathrm{~nm})$ и блокирующего остальные длины волн, сигнал поступает на поляризационно-голографическую дифракционную решетку анизотропного профиля для дальнейшего анализа.

Картина дифракции восстановленного изображения на поляризационно-голографическую дифракционную решетку анизотропного профиля для образцов автомобильных бензинов аналогична, только в этом случае на решетку для анализа сигнал поступал из интервала длин волн, в котором сравнительно велика степень поляризации фотолюминесценции образцов (параметр $P$ ). Полученные результаты хорошо согласуются с теорией $[13,15]$.

Отметим, что когда на поляризационно-голографическую дифракционную решетку анизотропного профиля падает полный спектр люминесценции восстановленного изображения волнового поля объекта, в положительном и отрицательном порядках дифракции можно наблюдать несколько изображений анизотропно-гиротропного объекта, одновременно с разными частотами эмиссии и состоянием поляризации. Мультиплексное детектирование затрудняется, так как спектры эмиссии люминофоров сильно перекрываются.

\section{Заключение}

Получены образцы люминесцентных фотоанизотропных голограммных сред на базе грузинской сырой нефти Сацхенисского месторождения из различных буровых, а также образцов автомобильных бензинов различных марок.

Получены спектры люминесценции и поляризационные спектры сред, в зависимости от их состава и химической структуры.

Показано, что при одинаковых условиях наведения анизотропии, в пробах сырой нефти из различных буровых, наблюдаются различия величин степени поляризации фотолюминесценции и интенсивности поляризованной люминесценции (параметров $P$ и $I$ ), что позволяет судить о природе молекул различных углеводородов находящихся в пробе, следовательно, о качестве сырой нефти.

Показано, что под действием возбуждающего линейно-поляризованного излучения с длиной волны $405 \mathrm{~nm}$, в автомобильных бензинах с различным октановым числом наблюдаются характерные изменения степени поляризации абсолютной величины и перемены знака, что дает возможность рассматривать поляризационные спектры в качестве дополнительной аналитической характеристики люминесцирующего битуминозного топлива.

Обнаружен эффект поляризационной памяти фотолюминесценции к линейной поляризации возбуждения в исследуемых битуминозных голограммных средах поворот поляризации возбуждающего лазерного излучения приводил к повороту плоскости поляризации $F L$; влияние поляризации возбуждающего излучения на парметры $F L$ может трактоваться как поляризационная память люминесценции исследуемых битуминозных голограммных сред.

Проведено экспериментальное исследование поляризационных свойств люминесцентной отражательной голограммы Денисюка, полученной в фотоанизотропногиротропном материале с использованием линейно поляризованного когерентного света. Показано, что состояние поляризации восстановленного поля объекта частично линейно поляризовано.

В дальнейшем предполагается проведение исследований других битуминозных материалов при различных длинах волн засветки и состояния поляризации актиничного излучения. Это даст возможность создания сред для задач поляризационно-люминесцентной голографии с управляемыми параметрами фотоиндуцированной люминесценции, проведение исследований пропускающей поляризационной люминесцентной голограммы, полученной по методу Лейта-Упатниекса.

В заключение отметим, что метод исследования поляризационно-люминесцентных характеристик битуминозных материалов, примененный в данной работе, также может представлять интерес для использования его при диагностике нефтяных загрязнений, контроля качества углеводородных топлив и их идентификации. 


\section{Список литературы}

[1] Weigert F. // Verh. Dtsch. Phys. Ges. 1919. V. 21. P. 479.

[2] Weigert F. // Ann. Phys. 1920. V. 63. P. 682.

[3] Какичашвили Ш.Д. // Открытия, изобретения. 1979. № 38.

[4] Nikolova L., Todorov T., Ivanov M., Andruzzi F., Hvilsted S., Ramanujam P.S. // Appl. Opt. 1996. V. 35. P. 3835.

[5] Tsutsumi N., Yabuhara Y., Kinashi K., Sakai W. // Optical Mater. Express. 2017. V. 7. P. 1647.

[6] Какичашвили Ш.Д., Тарасашвили В.И. // Опт. и спектр. 1986. T. 60. № 5. C. 1071.

[7] Шавердова В.Г., Петрова С.С., Пурцеладзе А.Л., Тарасашвили В.И., Оболашвили Н.З. // Опт. и спектр. 2017. T. 123. № 3. C. 458.

[8] Obukhov A.E. // Laser Physics. 1997. V. 7. N 5. P. 1102.

[9] Туранова О.А., Шарыпова А.Р., Суханов А.А. и др. // Нефтехимия. 2010. Т. 50. № 6. С. 472.

[10] Хундадзе М.А. // Труды ТГУ Т. 1968. Т. 126. С. 11.

[11] Компан М.Е., Шабанов И.Ю., Хиляев Ю.В. // Физика твердого тела. 2000. Т. 42. № 6. С. 1009.

[12] Денисюк Ю.Н. // Опт. и спектр. 1963. Т. 15. № 4. С. 522.

[13] Пуриеладзе А.Л., Тарасашвили В.И., Шавердова В.Г., Петрова С.С. // ЖПС. 2014. Т. 81. № 1. С. 65.

[14] Танин Л.В., Танин В.А. // Мир Голографии. 2017. Т. 3. № 1. C. 4.

[15] Толстик А.Л. // Мир Голографии. 2017. Т. 3. № 1. С. 24.

[16] Какичашвили Ш.Д., Шаталин И.Д. Поляризационные решетки анизотропного профиля на основе протравных азокрасителей. Фотоанизотропные и фотогиротропные явления в конденсированных средах и поляризационная голография, Тбилиси: Мецниереба, 1987, С. 72.

[17] Бабушкин А.А., и др. Методы спектрального анализа. М.: МГУ, 1962. $509 \mathrm{c}$.

[18] Вавилов С.И. Собр. соч. М.: 1952. 129 с.

[19] Архипов М.И. // Проблемы обеспечения безопасности при ликвидации последствий чрезвычайных ситуаций материалы конференции. 2013. Т. 1. № 1. С. 225. 